Review

\title{
Adolescent Cellphone Use While Driving: An Overview of the Literature and Promising Future Directions for Prevention
}

\author{
M. Kit Delgado ${ }^{1, *}$, Kathryn J. Wanner ${ }^{1}$ and Catherine McDonald ${ }^{2}$ \\ ${ }^{1}$ Perelman School of Medicine, University of Pennsylvania, Philadelphia, PA 19104, USA; \\ E-Mails: kit.delgado@uphs.upenn.edu (M.D.), Kathryn.Wanner@uphs.upenn.edu (K.J.W.) \\ ${ }^{2}$ School of Nursing, University of Pennsylvania, Philadelphia, PA 19104, USA; E-Mail: mcdonalc@nursing.upenn.edu \\ * Corresponding author
}

Submitted: 17 December 2015 | Accepted: 11 March 2016 | Published: 16 June 2016

\begin{abstract}
Motor vehicle crashes are the leading cause of death in adolescents, and drivers aged 16-19 are the most likely to die in distracted driving crashes. This paper provides an overview of the literature on adolescent cellphone use while driving, focusing on the crash risk, incidence, risk factors for engagement, and the effectiveness of current mitigation strategies. We conclude by discussing promising future approaches to prevent crashes related to cellphone use in adolescents. Handheld manipulation of the phone while driving has been shown to have a 3 to 4 -fold increased risk of a near crash or crash, and eye glance duration greater than 2 seconds increases crash risk exponentially. Nearly half of U.S. high school students admit to texting while driving in the last month, but the frequency of use according to vehicle speed and high-risk situations remains unknown. Several risk factors are associated with cell phone use while driving including: parental cellphone use while driving, social norms for quick responses to text messages, and higher levels of temporal discounting. Given the limited effectiveness of current mitigation strategies such as educational campaigns and legal bans, a multi-pronged behavioral and technological approach addressing the above risk factors will be necessary to reduce this dangerous behavior in adolescents.
\end{abstract}

\section{Keywords}

accidents prevention; adolescent; cell phones; distracted driving; text messaging

\section{Issue}

This review is part of the issue "Adolescents in the Digital Age: Effects on Health and Development", edited by Dan Romer (University of Pennsylvania, USA).

(C) 2016 by the author(s); licensee Cogitatio (Lisbon, Portugal). This article is licensed under a Creative Commons Attribution 4.0 International License (CC BY).

\section{Introduction}

Cellphones, and the connectivity they provide, have become a part of everyday life. In recent years, cellphone use, in particular communication by text messaging, has dramatically increased in prevalence and popularity across the world. In 2014, an estimated 169.3 billion text messages were sent worldwide, compared to 110 billion in 2009 (CTIA, 2013). Adolescents report that texting is the most common way that they stay in contact with friends (Lepp, Barkley, \& Karpinski, 2014), sending an average of 100 texts per day (Nielson, 2010). Problematic cellphone use and texting has been likened to other addictive behaviors, and may have negative effects on both academic performance and mental health (Lee, Chang, Lin, \& Cheng, 2014; Lepp, et al., 2014; Walsh, White, \& Young, 2008). However, texting has also become a way that adolescents forge social bonds, and texting between adolescents often serves to promote social cohesion in peer groups (Ling, 2012). More than half of adolescents text their friends every day, and many of them are texting their friends multiple times a day (Lenhart, Smith, Anderson, Duggan, \& Perrin, 2015).

The phenomenon of distracted driving from cellphone use has caught the attention of the national 
media in the United States (U.S.). There have been numerous reports on its dangers (CNN, 2014; DePalma, 2014; Muskal, 2015), prevalence (Richtel, 2015), and possible solutions (Richtel, 2014). The U.S. federal government's Healthy People 2020 objectives pinpoints distracted driving related to cellphone use as the top emerging cause of injury and highlights the need for future research (Office of Disease Prevention and Health Promotion, 2015). Several prominent public awareness campaigns have been aimed at promoting safety while driving, and in 2010 there was a national summit that brought together safety experts, senators, and industry leaders, to focus on this issue (AAA, 2013). Given the gravity of the problem of distracted driving, and in concert with this special issue on "Adolescents in the Digital Age: Effects on Health and Development," the objectives of this paper are to provide an overview on the incidence, crash risk, risk factors for engagement, and the effectiveness of current mitigation strategies. We conclude by proposing promising future approaches to prevent crashes due to cellphone use in adolescents.

\section{Public Health Magnitude of Distracted Driving in Adolescents}

Motor vehicle crashes (MVCs) are the leading cause of death and disability in adolescents in the U.S. and globally (World Health Organization, 2013). Based on police crash report data collected by the U.S. National Highway Traffic Safety Administration (NHTSA), in 2013, 2,650 adolescents, aged 16-19, died as a result of a motor vehicle collision (MVC), making this the number one cause of death in the U.S. for this age group; another 292,000 were treated for injuries (CDC, 2013). A disproportionate amount of MVCs related to distracted driving involve teenagers: although they comprise $6 \%$ of all drivers killed in MVCs, teenagers account for $10 \%$ of all drivers determined to be distracted at the time of a crash and $11 \%$ of all drivers killed in crashes related to documented cellphone use (NHTSA, 2015b). NHTSA reports that there were a total 45 teenage drivers and 161 drivers (aged 20-29) killed in cellphone distraction crashes in 2013. These numbers underestimate the true magnitude of the problem since the statistics are based on documented cellphone use while driving as measured through police reports.

\section{Incidence of Cellphone Use While Driving in Adolescents}

The majority of evidence on the proportion of the adolescent population that uses their cellphone while driving has been obtained through population-level selfreport surveys. In 2014, 94\% of U.S. drivers aged 18-29 reported owning a smartphone (State Farm, 2014). A Centers for Disease Control and Prevention survey of 8,505 students 16 years of age and younger, found that
$42 \%$ of U.S. high school students admit to engaging in texting while driving, which included both text messaging and emailing while driving, at least once per month (Olsen, Hanowski, Hickman, \& Bocanegra, 2009). A more recent nationally representative survey of 1,243 high school students, funded by the National Institutes of Health $(\mathrm{NIH})$, found that $83 \%$ reported engaging in electronic device use while driving at least once in the last 30 days (Ehsani, Li, \& Simons-Morton, 2015). Specifically, $71 \%$ made or answered a phone call, $64 \%$ read or sent a text message, $20 \%$ read or sent an email, $29 \%$ checked a website, $71 \%$ changed music, $12 \%$ used a tablet, and $53 \%$ looked at directions or a map. Young drivers reported using electronic devices while driving on $19 \%$ of the days they drove. Males were more likely to use a tablet or a computer while driving, teens from moderate and high affluence households were more likely to check websites, and rural participants were less likely to look at directions or a map than urban participants (Ehsani et al., 2015).

It appears that social media use while driving is increasing among adolescents and young adults based on a survey, conducted annually since 2009 by the State Farm insurance company, of 1,000 drivers, aged 18 and older. According to this survey, the proportion of young drivers, aged 18-29, who read social media websites while driving doubled from $21 \%$ in 2009 to $41 \%$ in 2014 (State Farm, 2014). Likewise, the proportion of this population who actually post to social media while driving increased from $20 \%$ in 2009 to $30 \%$ in 2014. This form of communication may eventually supplant text messaging, as the same survey found the proportion of young adults age 18-29 who texted while driving was 58\% in 2014, down from $71 \%$ in 2009.

NHTSA's National Occupant Protection Use Survey (NOPUS) provides the only nationwide probabilitybased observed data on driver electronic device use in the U.S. Data are collected by trained observers standing at the roadside of probabilistically sampled intersections, who are observing drivers while stopped at the intersection. The overall percentage of drivers who are text-messaging, or visibly manipulating handheld devices while driving, increased from 1.7 $\%$ in 2013 to $2.2 \%$ in 2014 . However, among the $16-$ 24 year old age group, this proportion was much higher, and increased from $2.9 \%$ in 2013 to $4.8 \%$ in 2014 (NHTSA, 2015a). These statistics likely underestimate the true incidence of handheld cellphone use since the below eye-level view beneath the windows and windshield is not captured.

Local roadside observation based studies suggest a higher prevalence of cellphone use while driving. A study conducted at 11 intersections in the Birmingham Alabama metro area found that among drivers presumed to be less than 30 years olds $(N=853), 8.4 \%$ were observed to be texting and another $11.7 \%$ were observed to be talking on the phone (Huisingh, Griffin, 
\& McGwin, 2015). Among drivers of all ages who were witnessed to be texting, $49 \%$ of these episodes were at estimated speed of more than 25 miles per hour. A similar study conducted in one intersection in Pennsylvania in 2014 of 2,000 observed drivers, found $3 \%$ of drivers in motion were texting or visibly manipulating handheld devices and 5\% were engaged in handheld phone calls. Among the stopped drivers, $14.5 \%$ were texting and $6.3 \%$ were talking (Bernstein \& Bernstein, 2015). Further work is necessary to describe the proportion of time individual drivers use their phone while the car is in motion.

Naturalistic studies using non-obtrusive video event recorders installed in drivers' cars can provide a much more nuanced incidence of cellphone use and other distracted driving behaviors. Typically, the recorder runs continuously, it only saves information when a vehicle movement (decelerating, accelerating, or turning) produces a g-force that exceeds a predetermined threshold. Lower thresholds can be set such that clips can be recorded intermittently during normal periods of driving. A naturalistic study using event-triggered recording in 52 high-school aged drivers found that cellphone use was present in $6.7 \%$ video clips, followed by adjusting vehicle controls (6.2\%) and grooming (3.8\%) (Foss \& Goodwin, 2014). Of episodes of cellphone use, one third involved holding the phone to the ear, with the rest involving handheld manipulation. Only $1 \%$ of these recorded episodes involved hands-free talking. Interestingly, cellphone use while driving was much less likely to occur if there was a passenger in the vehicle.

A naturalistic study using continuous video recording of young drivers $20-30$ years old $(n=36)$ for 4 weeks in 2006-2007 found that these drivers had a mean 2.1 phone conversations per hour for drive time for a mean average conversation duration of 2.6 minutes (Funkhouser \& Sayer, 2012). They also had a mean average of 4.0 visual-manual cellphone use task per hour of drive time with a mean average duration of 0.51 minutes. When data from all drivers aged $20-70$ years old was analyzed $(n=108)$, it was found that $23 \%$ of all visual manual tasks were initiated when stopped and another $5 \%$ were initiated at 5 miles per hour or less. Of concern, this indicated that nearly three quarters of handheld phone use episodes occurred while moving. In fact, more than $45 \%$ of these episodes were initiated at speeds of more than 25 miles per hour, consistent with the estimated $49 \%$ of texting episodes witnessed in the roadside observation study from Alabama (Huisingh et al., 2015). Given that speed is the biggest predictor of injury severity in motor vehicle collisions (Kockelman \& Kweon, 2002), these findings suggest that the riskiness of cellphone use episodes in terms of causing serious crashes is likely to be heterogeneous, and needs further clarification in future research (see Knowledge gaps).

\section{Safety Risk of Engaging in Cellphone Use While Driving}

The first large scale study to evaluate the safety risk of cellphone use while driving was published in the New England Journal of Medicine in 1997 (Redelmeier \& Tibshirani, 1997). This epidemiologic study compared detailed time-stamped phone bill usage records of individuals, moments before a motor vehicle crash as well as records one week before the crash. The risk of collision was found to be 4 times higher during a phone call. However, subsequent research has suggested a bias to this design; study subjects were less likely to have been driving during the control period, reducing their potential exposure to a crash (Young, 2012). Since then, dozens of studies with more robust designs have been published evaluating the risk of cellphone use while driving, and in particular texting while driving, in adult drivers. A meta-analysis of 28 epidemiologic, driving simulator, and naturalistic studies, which use vehicle instrumentation to measure actual driving, found that texting while driving increases the risk of crashing by at least 3 to 4-fold (Caird, Johnston, Wilness, Asbridge, \& Steel, 2014).

Fewer studies have examined the crash risk of cell phone use among adolescent drivers. Klauer et al. (2014) recently conducted a systematic review of quantitative epidemiologic, driving simulator, and naturalistic studies examining secondary task engagement while driving with adolescents; they identified 15 studies that met inclusion criteria (Klauer et al., 2014). Although this systematic review investigated more than just cell phone use (secondary task was defined as eating, using a cellphone, inserting a compact disc), their findings about the common mechanism that increases crash risk is notable. Overall, this systematic review found that secondary tasks while driving, where eyes were not on the forward roadway, increased crash risk (e.g. looking down at a phone while texting) (Fitch, Hanowski, \& Guo, 2014; Klauer, Dingus, \& Neal, 2006; Olsen et al., 2009); however, secondary tasks where eyes were not required to be off the forward roadway (e.g. talking on a cell phone) did not significantly increase crash risk (Harbluk, Noy, Trbovich, \& Eisenman, 2007; Klauer, Ehsani, McGehee, \& Manser, 2015).

One of the most rigorous studies included in Klauer et al.'s review followed 42 newly licensed adolescent drivers for 18 months immediately after licensure with in-vehicle event-triggered cameras (Klauer et al., 2014). This study found that dialing the phone was associated with the highest risk of a crash or near crash event (Odds Ratio [OR] 8.32), followed by reaching for the phone (OR 7.05), and texting or using the Internet (OR 3.87); talking was not associated with the crash risk (OR 0.61). Secondary analysis of these data revealed that the duration of glancing away from the forward roadway steadily increases the risk of a crash beginning 
with glances longer than 1 second. Glances of 2 seconds or more while engaging in handheld cellphone use were associated with a 5.5-fold increase in the risk of crash or near crash event (Simons-Morton, Guo, Klauer, Ehsani, \& Pradhan, 2014). These important findings imply that interventions and policies to reduce the crash risk of distracted driving, and in particular distraction from cellphone use, need to focus on maintaining the driver's eyes on the forward roadway.

\section{Knowledge of the Risks of Cellphone Use}

Generally, adolescents report that texting or talking on a handheld phone while driving is dangerous. A survey found that the $97 \%$ of U.S. adolescents know texting and driving is dangerous based on a survey of 1,200 teenagers aged 15-19 years old (AT\&T, 2012). However, knowledge of safety risks does not necessarily indicate adolescents will not engage in the behavior. In a focus group study of 16-18 year olds with less than 1 year of licensure, participants indicated that they understand the dangers of cellphone use while driving, however, they still reported driving while engaging in talking, texting and social media app use (McDonald \& Sommers, 2015). This suggests that simply continuing to raise awareness of the risks of cellphone use while driving may not be very effective for reducing this behavior, given that most adolescents are aware of the risks. A recent survey of college students found they were much more likely to text behind the wheel than drink and drive, despite perceiving that the risks of texting were similar to drinking (Terry \& Terry, 2015). Furthermore, participants perceived their peers as being more accepting toward cellphone use while driving than themselves, suggesting that one factor underlying the discrepancy between perceived risk and risk exposure may be the weakness of social norms opposed to texting while driving.

\section{Risk Factors for Engagement: Development, Peers and Families}

Adolescents are a particularly vulnerable group at risk for crashes. Adolescent drivers are at greatest risk for a crash in the first 6-12 months of licensure (Mayhew, Simpson, \& Pak, 2003; McCartt, Shabanova, \& Leaf, 2003; Williams \& Tefft, 2014). As adolescents drive, they acquire more experience and skill; this skill acquisition for newly licensed drivers strongly influences crash risk reduction in the first year of driving (McKnight \& McKnight, 2003). However, experience is not the only contributor to crashes, as the developmental changes during adolescence can influence crash risk.

Major changes in the brain occur throughout adolescence that can lead to increased risk taking and sensation seeking, and a movement towards a greater affiliation with their peers (Giedd, 2012). This is not to indicate that adolescents are taking risks with their cell phones while driving simply to challenge safety limits. Rather, adolescents may drive with incomplete maturation of cognitive and motor skills, and decisionmaking may be modulated by emotional and social factors.(Romer, Lee, McDonald, \& Winston, 2014) The adolescent pre-frontal cortex has not fully matured; adequate experience in risk assessment may not have occurred, nor may adolescents fully exert control over those risks-and all the while, there is a rise in sensation seeking (Giedd, 2012). Impulsivity and present biased preferences (Atchley \& Warden, 2012), the tendency to place more weight on benefits realized now and less weight on costs realized in the future, is associated with a higher likelihood of engaging in texting while driving (Hayashi, Russo, \& Wirth, 2015). Adolescents are more present-biased than adults indicating a greater cognitive difficulty with delaying gratification (Romer, Duckworth, Sznitman, \& Park, 2010), and in this context, delaying checking their phone and/or responding to a text message until they have stopped driving.

A 2014 systematic review of 29 papers identified several other psychological factors associated with cellphone use while driving in young drivers. These included the importance of an incoming or outgoing call, social acceptance, possession attachment, and a positive attitude toward cellphone use while driving (Cazzulino, Burke, Muller, Arbogast, \& Upperman, 2014). The importance of answering or making the call while driving was found to have greater weight than the perceived risk associated with cellphone use while driving.

The proximity of relationship of the individual who is communicating with the adolescent influences cellphone use (Atchley \& Warden, 2012; LaVoie, Lee, \& Parker, 2015). In a focus group study, adolescent participants indicated that context mattered; the individual involved in the communication, and the reason behind it, would influence whether they would use the cell phone while driving (McDonald \& Sommers, 2015). A survey study of 395 adolescent drivers found that adolescents most often spoke to parents while driving $(50 \%)$, rather than a significant other $(16 \%)$ or friend (21\%) (LaVoie et al., 2015). This indicates that reducing check in calls from parents may reduce cellphone use while driving. However, adolescent drivers were more likely to text a significant other (30\%) or friend $(27 \%)$ rather than their parents (16\%) (LaVoie et al., 2015). Social norms strongly influence texting behavior, as $89 \%$ of adolescents expect a response to a text message within 5 minutes (Bowen et al., 2009). Together these findings indicate that interventions to reduce texting should alleviate the urge to respond immediately to close social contacts, such as setting up automated responses to incoming text messages.

Carter, Bingham, Zakrajsek, Shope and Sayer (2014) also conducted a survey with adolescent-parent dyads and found that actual and perceived distracted driving behaviors of parents, and perceived distracted driving 
behaviors of peers, were predictive of adolescent distracted driving behavior. Finally, there is increasing evidence for compulsive cellphone use as a diagnosable behavioral addiction, given the behavioral and neurobiological characteristics of this behavior (Billieux, Maurage, Lopez-Fernandez, Kuss, \& Griffiths, 2015). Use in dangerous situations, such as while driving, is measured as a factor in scales of problematic cellphone use (Merlo, Stone, \& Bibbey, 2013). More research is needed to better determine the correlation between measures of general problematic or compulsive phone use and risky cellphone use while driving.

\section{Social and Logistical Barriers to Reducing Cellphone Use While Driving}

Understanding why adolescents may not want to abstain from in-vehicle cellphone use provides insights into behavioral strategies that may be more effective for reducing use while driving. Dominant disadvantages of abstaining from in-vehicle cellphone use among adolescents include: the inability to communicate location or letting others know their time of arrival, the inability to get help if the driver got lost or forgot something, and increased difficulty for parents to get in touch with the driver (Hafetz, Jacobsohn, García-España, Curry, \& Winston, 2010). Other disadvantages of abstaining from in-vehicle cellphone use are giving up the ability to call for emergency help. This may include calling 911 if being followed by a potential stalker, calling to report a drunk driver on the road, or calling for emergency medical care in the case of a MVC. In fact, in the landmark 1997 New England Journal of Medicine study on drivers who owned cellphones and were involved in MVCs, 39\% of drivers called 911 from the scene of the crash on their cellphone (Redelmeier \& Tibshirani, 1997). Therefore, interventions to reduce risky cellphone use while driving should make allowances for calls in emergency situations and should safely balance needs related to navigation and trip communication.

\section{Effectiveness of Current Mitigation Strategies}

\subsection{Legal Bans}

In the U.S., states have enacted policies to help decrease cellphone use while driving. For example, according to the Insurance Institute of Highway Safety (2015), as of the end of December 2015, talking on a hand-held cellphone while driving has been banned for all drivers in 14 states and the District of Columbia; additionally, the use of all cellphones by novice drivers is restricted in 37 states and the District of Columbia. Text messaging has been banned for all drivers in 46 states and the District of Columbia. In addition, novice drivers are banned from texting in Missouri and Texas (Insurance Institute for Highway Safety, 2015).
There are mixed results on the effectiveness of cellphone restrictions. One of the earliest studies examining the effect on the general population investigated the relationship between collision claim frequencies and texting bans in 4 states (Highway Loss Data Institute, 2010). This study found that texting bans were actually associated with increased frequencies of collision claims. The authors posited that this increase may have stemmed from the unintended consequence of drivers lowering their phones from view to avoid citations and fines and, in doing so, taking their eyes off the road more than they did before the implementation of the bans. Two other studies using observation and self-report outcomes in the adolescent driver population showed that laws restricting cellphone use have not had long-term effects on adolescent drivers' cellphone use while driving (Ehsani, Bingham, lonides, \& Childers, 2014; Goodwin, O'Brien, \& Foss, 2012).

Studies examining the effect of cell phone bans on MVC fatalities and hospitalizations have demonstrated modestly positive outcomes. Primary enforced laws banning all drivers from texting was associated with a $3 \%$ reduction in fatalities in all age groups; banning only young drivers from texting had the greatest impact on reducing deaths among those aged 15 to 21 years (Ferdinand et al., 2014). A similar study found an $8 \%$ decrease in fatalities in states that universally banned texting while driving and made it a primary offense. However, this effect was only apparent for the law's first three months (Abouk \& Adams, 2013). The study also found that this loss of effect was lessened in states that had universal bans against handheld use of cell phones. The authors suggest that the lack of effectiveness of texting bans was due to poor enforcement; drivers refrained from texting immediately after the law's announcement and implementation but returned to texting if they believed the law was not being enforced (Abouk \& Adams, 2013). Finally, texting bans were also significantly associated with reductions in hospitalizations among those aged 22 to 64 years and those aged 65 years or older, but did not significantly reduce hospitalizations for adolescents (Ferdinand et al., 2015). While in these analyses it cannot be determined whether the crashes and hospitalizations analyzed were caused by distracted driving or not, these studies suggest that bans with primary enforcement can reduce the burden of injury from cellphone use. This is further supported by the results of a high visibility law enforcement campaign "Phone in One Hand, Ticket in the Other" implemented in Connecticut and New York, which was shown to have a modest reduction in observed handheld cellphone usage rates over the course of a year (Chaudhary, Cassanova-Powell, Cosgrove, Reagan, \& Williams, 2012). Given the logistical difficulty needed to enforce bans, such as catching a driver using a phone out of view, additional mitigation strategies may be necessary. 


\subsection{Education to Increase Awareness}

Several national public health campaigns have emerged aimed at the prevention of distracted driving. For example, NHTSA's distraction.gov is a national campaign to increase awareness of distracted driving through informational videos, facts, and personal narratives (Distraction.gov, 2015). There have been several industry sponsored campaigns aimed at the prevention of distracted driving, such as AT\&T's "It Can Wait" wait campaign, which encourages individuals to reach out to friends and family and to pledge to abstain from texting and driving (AAA, 2013; AT\&T, 2012). These campaigns consist of online pledges, where individuals can pledge to abstain from texting and driving, and educational videos with the goal of increasing awareness of the dangers of distracted driving. Despite these major investments, there are no data to suggest that these campaigns have had any effect on cellphone use while driving. Given $97 \%$ of adolescent drivers already know that cellphone use while driving is dangerous (AT\&T, 2012), solely increasing awareness of risks is unlikely to lead to wide scale behavior change.

There are few published studies of more targeted educational interventions in the adolescent driver population. One effective intervention led by staff from a pediatric trauma center hospital invited 61 student leaders from a local high school for a half-day educational session. The student leaders then went back to their two high schools to implement a yearlong peerto-peer campaign focused on a clear no texting while driving campaign (Unni, Morrow, Shultz, \& Tian, 2013). There was a decrease in unannounced observation of actual texting and driving (from $17 \%$ to $8 \%, p<0.001$ ) among high school students driving on roads near the school a year after the intervention compared to just prior to the intervention (Unni, et al., 2013).

\subsection{Technological Interventions}

Over the last decade, in-vehicle technologies have been developed and tested with the aim of improving adolescent driving behavior through monitoring and feedback. Feedback on g-force events, recorded using an in-vehicle event triggered video recording device in which parents were involved in the feedback loop, has been shown to be effective in reducing the occurrence of these near-crash events (Simons-Morton et al., 2013). Some auto insurance companies have moved to offer use of event-triggered video monitors and parental feedback on recorded driving errors and distracted driving behavior (American Family Insurance, 2016).

More recently, in the last five years, smartphone applications have been developed to directly measure cellphone use while driving. "Software only" applications rely on the phone's sensors (e.g. accelerometer and GPS) to determine whether the phone is traveling at a speed consistent with driving (e.g. $>25 \mathrm{mph}$ ). If traveling over a certain speed threshold, the application can be set to disable the phone unlock screen and block incoming and outgoing text messaging and calls. Most of these applications have been developed for the Android platform and there are currently dozens of such applications available in the Google Play store. Because of the more stringent developer restrictions of the iOS, there are fewer such applications available in the iTunes store. The major barriers to adoption of "software only" applications are the current inability to detect whether the phone is being used on a car vs. another vehicle such as a bus or train, and battery drain from continuous use of GPS in the background. "Software-Hardware" applications have also been developed to overcome some of these limitations. This involves the instillation of a device in the car that pairs with a smartphone application via Bluetooth technology. These devices were developed to be installed in the car's OBD-II (On-board diagnostics-II) data port and more recently have included solar powered designs that can be installed on the windshield.

To our knowledge there are three completed studies of smartphone applications to block cellphone use while driving, with all three demonstrating a reduction in cellphone use while driving at non-zero speeds (Creaser, Edwards, Morris, \& Donath, 2015; Ebel et al., 2015; Funkhouser \& Sayer, 2013). For example, in the largest study to date, involving 274 novice teen drivers followed for 1 year, the rate of text messages sent per mile driven for each given month post licensure was at least 5 to 10 times higher in the control group ( 0.05 to 0.20 texts per mile driven) than in the blocking group ( 0.0 to 0.02 texts per mile driven) (Creaser et al., 2015). The number of text messages sent tripled by one year since licensure in the control group compared with the first 8 months of driving. On the other hand, the rate remained stable in the blocking group (Creaser et al., 2015). However, behavioral engagement strategies will likely be necessary to enable the success and sustainability of cellphone blocking indicating a low likelihood of use beyond the study. In the above mentioned study, $15 \%$ of the teen drivers in the treatment group were caught trying to game the system either by finding ways to bypass the blocking system or by borrowing a phone (Creaser et al., 2015). In one study of adult drivers, after an intervention period of blocking was disabled, there was no lasting behavior change as cellphone use while driving returned to baseline levels (Funkhouser \& Sayer, 2013). Furthermore, when surveyed, the adult participants had overall not very positive views of the blocking technology.

\section{Knowledge Gaps in the Science}

Despite the widespread emergence of cellphone use while driving among adolescent drivers over the last 
decade, and the associated research activity on this behavior, several critical knowledge gaps persist. One of the major challenges in understanding the prevalence of this behavior and measuring effectiveness of intervention strategies is a lack of readily collectable, reliable, and valid measures of cellphone use while driving. Despite the ease of collection of survey data on magnitude of self-reported cellphone use while driving, there is scant evidence to support its validity. Based on the comparison between self-reported general smartphone use episodes and actual recorded episodes, survey self-report methods likely underestimate the number of cellphone use episodes (Andrews, Ellis, Shaw, \& Piwek, 2015). The biggest problem with widely accepted survey self-report measures of cellphone use while driving is that there is no distinction between use while stopped vs. use while the car is in motion (Olsen, Shults, \& Eaton, 2013). Only one study to our knowledge measured self-reported cellphone use and actual cellphone use while driving using a cellphone app and in vehicle monitoring device, but these measures were not directly compared (Creaser et al., 2015). There is a need for future naturalistic studies to clarify the correlation between self-reported cellphone use and actual cellphone use as well as the frequency and duration of use given the transient risks of the exposure on crash risk.

The association between driving context in which cellphone use is initiated and crash risk has also not been well elucidated. For example, it is not known if handheld use while stopped or in very low speed traffic actually poses risk of injury. Additionally, it is not known how type of handheld cellphone use (e.g. texting vs. checking email vs. looking at GPS directions) affects level of risk in terms eye glance duration, real driving performance, and near crash and crash events. These knowledge gaps are difficult to fill because they would require naturalistic studies with large sample sizes. Leveraging smartphone apps that can track type of phone use while driving may be a cost-effective way to study these questions in larger and broader populations than have been studied to date in instrumented vehicle naturalistic studies.

Furthermore, there is a great need to better understand the effectiveness of current countermeasures and assess why many countermeasures have failed to reduce this behavior. Specifically, it should be determined whether cellphone bans have led to the unintended consequence of drivers holding their phone below window-level view to avoid detection when texting thereby taking their eyes off the road longer. If confirmed, this could undermine the effectiveness of enforcing cellphone bans. Additionally, further qualitative research with adolescent drivers and their parents would shed light on addressable barriers to the adoption of several available smartphone based apps and settings that limit the temptation to text while driving.
Finally, as smartphone and in-vehicle technology rapidly evolves, there is an urgent need to determine whether hands-free features actually reduce cognitive distraction and keep the drivers eyes on the road. Studies to date suggest that most of these features, such as voice to text functions, do not reduce distracted driving and may even increase the risk of distraction (Strayer, Turrill, Coleman, Ortiz, \& Cooper, 2014).

\section{Promising Future Directions}

Given the limited effectiveness of current isolated mitigation strategies, a multi-pronged regulatory, behavioral, and technological approach addressing the above risk factors will be necessary to reduce this dangerous behavior in adolescents. For legal bans to be effective, they must be aggressively enforced. As evidenced by prior research, bans lose effectiveness shortly after implementation, likely due to lack of enforcement (Highway Loss Data Institute, 2010). As demonstrated in a pilot program in two northeastern U.S. states, high visibility law enforcement campaigns that increase awareness of the legal and financial repercussions of texting in addition to actually enforcing the bans, improve the effectiveness of the legal ban (Chaudhary, et al., 2012). It is also likely that increasing the financial and legal repercussions of getting caught using a cellphone while driving would further increase the effectiveness of legal bans. The combination of these approaches are theoretically sound given that individuals value and are more sensitive to losses than equivalent gains based on the behavioral economic phenomenon of loss aversion (Tversky \& Kahneman, 1991). Nevertheless, the logistical challenges of enforcing bans, particularly the accurate detection of the behavior (holding and manipulating phone in hand vs. holding another object or looking down in car) will continue to limit the overall effectiveness of bans, necessitating other strategies to reduce use.

Educational interventions aimed at reducing texting while driving and distracted driving in general should focus on targeting the mechanism by which distraction causes crashes-by getting drivers to keep their eyes on the forward roadway. Furthermore, efforts to reduce cellphone use while driving in adolescents may be more successful if the intervention also addresses the parents' behavior. There is promising evidence that active parental involvement enhances the effectiveness of adolescent driving interventions (Curry, Peek-Asa, Hamann, \& Mirman, 2015). Furthermore, given the strong correlation between parental engagement with texting and driving and their child's behavior, strategies that enable parents to be better role models for their children are highly promising (Carter et al., 2014). Educational interventions that can be delivered online would increase the scalability of these efforts and potential adoption in driver's education classes. 
While smartphone applications that disable handheld use while driving are effective in research settings, it is questionable whether individuals will continue to use such applications without a behavioral strategy to sustain use. This is evidenced by the fact that a significant proportion of adolescent drivers tried to bypass cellphone blocking in one study (Creaser et al., 2015). In the short term, the apps can be designed to be more user friendly by allowing automated responses to incoming messages and hands free navigation, enabling emergency calls, and balancing functionality with maintaining battery life. Incorporating adolescents and young adults into the design process would like also increased adoption. In the long term, as with all mobile devices and apps, sustaining use will require behavioral engagement strategies (Patel, Asch, \& Volpp, 2015). Feedback loops could be better designed to sustain engagement with cellphone blocking apps using concepts from behavioral economics. Given that some of those who engage in texting while driving overweigh immediate benefits (Hayashi et al., 2015), promising intervention would be to provide frequently delivered (e.g. daily) rewards to make the cognitive appraisal of abstaining from handheld phone use more attractive than the urge to engage in texting while driving (Loewenstein, Asch, \& Volpp, 2013). Making a portion of parental weekly allowances contingent on good behavior may be one way to operationalize this through the use of smartphone based apps that monitor cellphone use behavior while driving (e.g. \$1/day of allowance given for each day with no measured texting while driving). In the future, financial rewards could be scaled up and implemented on a large scale through repurposing existing auto-insurer teen driver discounts into discounts or rewards based on actual driving performance, as measured by in vehicle devices and smartphone applications (Cambridge Mobile Telematics, 2014). Auto insurance and car rental companies are already providing in-vehicle devices and associated smartphone applications to reduce cellphone distraction (Insurance and Technology, 2013; Jackson, 2016).

\section{Conclusions}

Cellphones are a mainstay of connectivity in most adolescents' daily lives, as a form of entertainment, information and communication. The pervasiveness of adolescent cellphone use can have negative effects on driving behavior and increase crash risk. Current strategies to decrease adolescent cellphone use while driving fall short of what is needed to curb teen driver crashes and improve adolescent health. Interdisciplinary approaches show promise, and those that integrate cellphone policies, technology, and individual and family behaviors will be necessary to reduce this dangerous behavior in adolescents.

\section{Acknowledgments}

This work was supported by Research Career Development Program in Emergency Medicine of the National Institutes of Health under award number K12HL109009 (Delgado), as well as the Penn Roybal Center for Behavioral Economics under award number P30AG034546 (Delgado). Catherine C. McDonald was supported by the National Institute of Nursing Research under award number R00NR013548. The content is solely the responsibility of the authors and does not necessarily represent the official views of the National Institutes of Health.

\section{Conflict of Interests}

The authors declare no conflict of interests.

\section{References}

AAA. (2013). AAA Campaign aims to pass texting while driving bans in all 50 states by 2013. AAA Newsroom. Retrieved from http://newsroom.aaa.com/2009/09/ 2009-heads-up-driving-wee

Abouk, R., \& Adams, S. (2013). Texting bans and fatal accidents on roadways: do they work? Or do drivers just react to announcements of bans? American Economic Journal: Applied Economics, 5(2), 179-199.

American Family Insurance. (2016). Teen safe driver program. Retrieved from http://www.teensafedriver. com

Andrews, S., Ellis, D., Shaw, H., \& Piwek, L. (2015). Beyond self-report: Tools to compare estimated and real-world smartphone use. PLoS One, 10(10), e0139004.

AT\&T. (2012). AT\&T teen driver survey: Executive summary. Retrieved from www.att.com/Common/about _us/txting_driving/att_teen_survey_executive.pdf

Atchley, P., \& Warden, A. C. (2012). The need of young adults to text now: Using delay discounting to assess informational choice. Journal of Applied Research in Memory and Cognition, 1(4), 229-234.

Bernstein, J. J., \& Bernstein, J. (2015). Texting at the light and other forms of device distraction behind the wheel. BMC Public Health, 15(1), 968.

Billieux, J., Maurage, P., Lopez-Fernandez, O., Kuss, D., \& Griffiths, M. (2015). Can disordered mobile phone use be considered a behavioral addiction? An update on current evidence and a comprehensive model for future research. Current Addiction Reports, 2(2), 156162.

Bowen, D., Kreuter, M., Spring, B., Cofta-Woerpel, L., Linnan, L., Weiner, D., . . Fernandez, M. (2009). How we design feasibility studies. American Journal of Preventive Medicine, 36(5), 452-457.

Caird, J., Johnston, K., Wilness, C., Asbridge, M., \& Steel, P. (2014). A meta-analysis of the effects of texting on 
driving. Accident Analysis and Prevention, 71, 311318.

Cambridge Mobile Telematics. (2014). Leading global insurer expands partnership with innovative telematics technology provider. Cambridge Mobile Telematics. Retrieved from http://www.cmtelematics.com/news /leading-global-insurer-expands-partnership-innovati ve-telematics-technology-provider

Carter, P., Bingham, C., Zakrajsek, J., Shope, J., \& Sayer, T. (2014). Social norms and risk perception: Predictors of distracted driving behavior among novice adolescent drivers. Journal of Adolescent Health, 54(5), S32-S41.

Cazzulino, F., Burke, R., Muller, V., Arbogast, H., \& Upperman, J. (2014). Cell phones and young drivers: A systematic review regarding the association between psychological factors and prevention. Traffic Injury Prevention, 15(3), 234-242.

CDC. (2013). Centers for Disease Control and Prevention. Web-based injury statistics query and reporting system (WISQARS). 2010. Retrieved from: www.cdc. gov/ncipc/wisqars

Chaudhary, N., Cassanova-Powell, T., Cosgrove, L., Reagan, I., \& Williams, A. (2012). Evaluation of NHTSA distracted driving demonstration projects in Connecticut and New York. Washington DC: National Highway Traffic Safety Administration.

CNN. (2014). Distracted driving a real danger for teens. CNN. Retrieved from http://www.cnn.com/2014/ 01/23/living/teens-driving-texting-drinking-parents

Creaser, J., Edwards, C., Morris, N., \& Donath, M. (2015). Are cellular phone blocking applications effective for novice teen drivers? Journal of Safety Research, 54(June), 75.e29-78.

CTIA. (2013). CTIA's wireless industry summary report, year end 2014 results. Computers in Human Behavior, 29(6), 2632-2639.

Curry, A. E., Peek-Asa, C., Hamann, C.,\& Mirman, J. (2015). Effectiveness of parent-focused interventions to increase teen driver safety: A critical review. Journal of Adolescent Health, 57(1), S6-S14.

DePalma, A. (2014). Did a text kill my brother? The New York Times. Retrieved from http://www.nytimes. com/2015/02/15/opinion/sunday/did-a-text-kill-mybrother.html

Distraction.gov. (2015). Official US government website for distracted driving. Retrieved from http://www. distraction.gov/index.html

Ebel, B., Boyle, L., O'Connor, S., Bresnahan, B., Maeser, J., Kernic, M., \& Rowhani-Rahbar, A. (2015). Randomized trial of cell phone blocking and in-vehicle camera to reduce high-risk driving events among novice drivers. Pediatric Academic Societies.

Ehsani, J., Bingham, C., Ionides, E., \& Childers, D. (2014). The impact of Michigan's text messaging restriction on motor vehicle crashes. Journal of Adolescent Health, 54(5), s68-s74.
Ehsani, J., Li, K., \& Simons-Morton, B. (2015). Teenage drivers portable electronic device use while driving. The National Academies of Sciences, Engineering Medicine, 219-225.

Ferdinand, A. O., Menachemi, N., Blackburn, J. L., Sen, B., Nelson, L., \& Morrisey, M. (2015). The impact of texting bans on motor vehicle crash-related hospitalizations. American Journal of Public Health, 105(5), 859-865. doi: 10.2105/AJPH.2014.302537

Ferdinand, A. O., Menachemi, N., Sen, B., Blackburn, J. L., Morrisey, M., \& Nelson, L. (2014). Impact of texting laws on motor vehicular fatalities in the United States. American Journal of Public Health, 104(8), 1370-1377. doi: 10.2105/ajph.2014.301894

Fitch, G., Hanowski, R., \& Guo, F. (2014). The risk of a safety-critical event associated with mobile device use in specific driving contexts. Traffic Injury Prevention, 16(2), 124-132. doi:10.1080/15389588.2014. 923566

Foss, R., \& Goodwin, A. (2014). Distracted driver behaviors and distracting conditions among adolescent drivers. Journal of Adolescent Health, 54(5).

Funkhouser, D., \& Sayer, J. (2012). Naturalistic census of cell phone use. Transportation Research Record: Journal of The Transportation Research Board, 2321, 1-6. doi: 10.3141/2321-01

Funkhouser, D., \& Sayer, J. (2013). Cellphone filter/blocker techonology field test. Washington, DC: National Highway and Traffic Safety Administration.

Giedd, J. N. (2012). The digital revolution and adolescent brain evolution. The Journal of Adolescent Health, 51(2), 101-105. doi:10.1016/j.jadohealth.2012.06.002

Goodwin, A., O'Brien, N., \& Foss, R. (2012). Effect of North Carolina's restriction on teenage driver cell phone use two years after implementation. Accident Analysis \& Prevention, 48, 363-367.

Hafetz, J. S., Jacobsohn, L. S., García-España, J. F., Curry, A. E., \& Winston, F. K. (2010). Adolescent drivers' perceptions of the advantages and disadvantages of abstention from in-vehicle cell phone use. Accident Analysis \& Prevention, 42(6), 1570-1576.

Harbluk, J., Noy, Y., Trbovich, P., \& Eisenman, M. (2007). An on-road assessment of cognitive distraction: Impacts on drivers' visual behavior and braking performance. Accident Analysis \& Prevention, 39, 372-379.

Hayashi, Y., Russo, C. T., \& Wirth, O. (2015). Texting while driving as impulsive choice: A behavioral economic analysis. Accident Analysis \& Prevention, 83, 182-189. doi:10.1016/j.aap.2015.07.025

Highway Loss Data Institute. (2010). Texting laws and collision claim frequencies. Ruckersville, VA: Highway Loss Data Institute.

Huisingh, C., Griffin, R., \& McGwin, G. (2015). The prevalence of distraction among passenger vehicle drivers: A roadside observational approach. Traffic Injury Prevention, 16(2), 140-146. doi:10.1080/15389588. 2014.916797 
Insurance and Technology. (2013). Esurance takes on distracted driving. Information Week. Retrieved from http://www.insurancetech.com/esurance-takes-ondistracted-driving/d/d-id/1314459?

Insurance Institute for Highway Safety. (2015, December 2015). Cellphones and texting: Map of texting bans. Retrieved from http://www.iihs.org/iihs/topics/laws/ cellphonelaws/maptextingbans?topicName=Distract ed driving \\# map

Jackson, C. (2016). TextNinja makes a game of banning texting while driving. Chicago Tribune. Retrieved from http://www.chicagotribune.com/bluesky/origin als/ct-textninja-safe-driving-bsi-20160219-story.html

Klauer, S., Dingus, T., \& Neal, V. (2006). The impact on driver inattention on near crash/crash risk: An analysis using the 100 car naturalistic driving study data. Washington, DC: National Highway Traffic Safety Administration.

Klauer, S. G., Ehsani, J. P., McGehee, D. V., \& Manser, M. (2015). The effect of secondary task engagement on adolescents' driving performance and crash risk. Journal of Adolescent Health, 57(1), S36-S43.

Klauer, S. G., Guo, F., Simons-Morton, B. G., Ouimet, M. C., Lee, S. E., \& Dingus, T. A. (2014). Distracted driving and risk of road crashes among novice and experienced drivers. New England Journal of Medicine, 370(1), 54-59.

Kockelman, K. M., \& Kweon, Y.-J. (2002). Driver injury severity: An application of ordered probit models. Accident Analysis \& Prevention, 34(3), 313-321.

LaVoie, N., Lee, Y.-C., \& Parker, J. (2015). Preliminary research developing a theory of cell phone distraction and social relationships. Accident Analysis \& Prevention, 86, 155-160.

Lee, Y.-K., Chang, C.-T., Lin, Y., \& Cheng, Z.-H. (2014). The dark side of smartphone usage: Psychological traits, compulsive behavior and technostress. Computers in Human Behavior, 31, 373-383.

Lenhart, B. Y. A., Smith, A., Anderson, M., Duggan, M., \& Perrin, A. (2015). Teens, technology, and freindship: Pew Research Center. Retrieved from http://www. pewinternet.org/2015/08/06/teens-technology-andfriendships

Lepp, A., Barkley, J., \& Karpinski, A. (2014). The relationship between cell phone use, academic performance, anxiety, and satisfaction with life in college students. Computers in Human Behavior, 31(1), 343-350.

Ling, R., Bertel, T., \& Sundsoy, P. (2012). The sociodemographics of texting: An analysis of traffic data. New Media \& Society, 14(2), 281-298.

Loewenstein, G., Asch, D., \& Volpp, K. (2013). Behavioral economics holds potential to deliver better results for patients, insurers, and employers. Health Affairs, 32(7), 1244-1250.

Mayhew, D. R., Simpson, H. M., \& Pak, A. (2003). Changes in collision rates among novice drivers during the first months of driving. Accident Analysis \& Preven- tion, 35(5), 683-691.

McCartt, A. T., Shabanova, V. I., \& Leaf, W. a. (2003). Driving experience, crashes and traffic citations of teenage beginning drivers. Accident Analysis and Prevention, 35(3), 311-320.

McDonald, C. C., \& Sommers, M. S. (2015). Teen drivers' perceptions of inattention and cell phone use while driving. Traffic Injury Prevention, 16, S52-58.

McKnight, J., \& McKnight, S. (2003). Young novice drivers: Careless or clueless? Accident Analysis and Prevention, 35(6), 921-925.

Merlo, L. J., Stone, A. M., \& Bibbey, A. (2013). Measuring problematic mobile phone use: Development and preliminary psychometric properties of the PUMP scale. Journal of Addiction, 2013.

Muskal, M. (2015). Teen drivers distracted by cellphones, talking in most crashes. Los Angeles Times. Retrieved from http://www.latimes.com/nation/lana-distraction-teen-crashes-20150325-story.html

NHTSA. (2015a). Driver electronic device use in 2014. U.S. Department of Transportation. Retrieved from http://www-nrd.nhtsa.dot.gov/Pubs/812197.pdf

NHTSA. (2015b). Traffic safety facts: Distracted driving 2013. NHTSA's National Center for Statistics and Analysis. Washington, DC: U.S. Department of Transportation. Retrieved from http://www.distraction. gov/downloads/pdfs/Distracted_Driving_2013_Rese arch_note.pdf

Nielson. (2010). U.S. teen mobile report calling yesterday, texting today, using apps tomorrow. The Nielson Company. Retrieved from http://www.nielsen.com/ us/en/insights/news/2010/u-s-teen-mobile-reportcalling-yesterday-texting-today-using-apps-tomorro w.html

Office of Disease Prevention and Health Promotion. (2015). Healthy People 2020. Retrieved from http:// www.healthypeople.gov

Olsen, E. O. M., Shults, R. A., \& Eaton, D. K. (2013). Texting while driving and other risky motor vehicle behaviors among US high school students. Pediatrics, 131(6), e1708-e1715.

Olsen, R., Hanowski, R., Hickman, J., \& Bocanegra, J. (2009). Driver distraction in commercial vehicle operations. Washington DC: US Department of Transportation.

Patel, M. S., Asch, D. A., \& Volpp, K. G. (2015). Wearable devices as facilitators, not drivers, of health behavior change. Journal of the American Medical Association, 313(5), 459-460.

Redelmeier, D. A., \& Tibshirani, R. J. (1997). Association between cellular-telephone calls and motor vehicle collisions. New England Journal of Medicine, 336(7), 453-458.

Richtel, M. (2014). Trying to hit the brake on texting while driving. The New York Times. Retrieved from http://www.nytimes.com/2014/09/14/business/tryi ng-to-hit-the-brake-on-texting-while-driving.html 
Richtel, M. (2015). Some people do more than text while driving. Bits. Retrieved from http://bits.blogs.ny times.com/2015/05/19/some-people-do-more-thantext-while-driving

Romer, D., Duckworth, A. L., Sznitman, S., \& Park, S. (2010). Can adolescents learn self-control? Delay of gratification in the development of control over risk taking. Prevention Science : The Official Journal of the Society for Prevention Research, 11(3), 319-330. doi:10.1007/s11121-010-0171-8

Romer, D., Lee, Y., McDonald, C., \& Winston, F. (2014). Adolescence, attention allocation, and driving safety. Journal of Adolescent Health, 54(5), S6--S15. doi:10.1016/j.jadohealth.2013.10.202

Simons-Morton, B. G., Bingham, C. R., Ouimet, M. C., Pradhan, A. K., Chen, R., Barretto, A., \& Shope, J. T. (2013). The effect on teenage risky driving of feedback from a safety monitoring system: A randomized controlled trial. Journal of Adolescent Health, 53(1), 21-26.

Simons-Morton, B. G., Guo, F., Klauer, S. G., Ehsani, J. P., \& Pradhan, A. K. (2014). Keep your eyes on the road: Young driver crash risk increases according to duration of distraction. The Journal of Adolescent Health, 54(5), S61-67.

State Farm. (2014). Distracted driving state. Farm Automobile Insurance Company. Retrieved from http:// teendriving.statefarm.com/road-to-safety/risky-drivi $\mathrm{ng} /$ distracted-driving
Strayer, D., Turrill, J., Coleman, J., Ortiz, E., \& Cooper, J. (2014). Measuring cognitive distraction in the automobile II: Assessing in-vehicle voice-based interactive technologies. Washington DC: AAA Foundation for Traffic Safety.

Terry, C. P., \& Terry, D. L. (2015). Distracted driving among college students: Perceived risk versus reality. Current Psychology, 35(1), 115-120.

Tversky, A., \& Kahneman, D. R. (1991). Loss aversion in riskless choice: A reference-dependent model. Quarterly Journal of Economics, 106(4), 1039-1061.

Unni, P., Morrow, S. E., Shultz, B. L., \& Tian, T. T. (2013). A pilot hospital-school educational program to address teen motor vehicle safety. Journal Trauma Acute Care Surgery, 75(4), S285-289.

Walsh, S. P., White, K. M., \& Young, R. M. (2008). Overconnected? A qualitative exploration of the relationship between Australian youth and their mobile phones. Journal of Adolescence, 31(1), 77-92.

Williams, A. F., \& Tefft, B. C. (2014). Characteristics of teens-with-teens fatal crashes in the United States, 2005-2010. Journal of Safety Research, 48, 37-42. doi:10.1016/j.jsr.2013.11.001

World Health Organization. (2013). Global status report on road safety: Time for action. Retrieved from: http://apps.who.int/iris/bitstream/10665/44122/1/9 789241563840_eng.pdf

Young, R. (2012). Cell phone use and crash risk: Evidence for positive bias. Epidemiology, 23(1), 116-118.

\section{About the Authors}

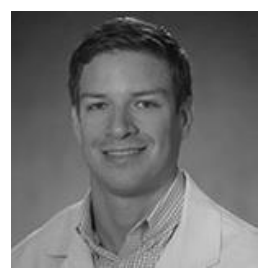

\section{Dr. M. Kit Delgado}

M. Kit Delgado, MD, MS, is an Assistant Professor in the Department of Emergency Medicine at the University of Pennsylvania. Dr. Delgado has secondary appointments as an Assistant Professor in the Department of Biostatistics and Epidemiology and as a Senior Fellow in the Leonard Davis Institute of Health Economics. Dr. Delgado's research focuses on reducing the public health burden caused by injury.

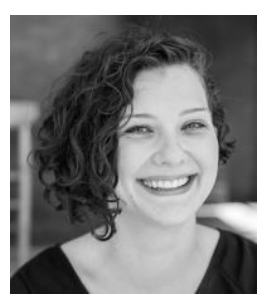

\section{Kathryn J. Wanner}

Kathryn J. Wanner, MA, is a Research Project Manager for the Center for Emergency Medicine Policy Research at the University of Pennsylvania. She received her Master of Art's in the Sociology of Education from New York University.

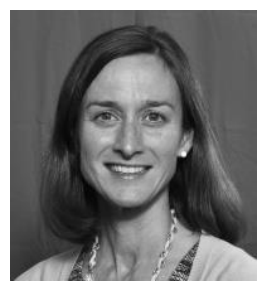

\section{Dr. Catherine McDonald}

Catherine McDonald, PhD, RN is an Assistant Professor at the University of Pennsylvania School of Nursing and has a secondary appointment at Children's Hospital of Pennsylvania as an Assistant Professor of Nursing in Pediatrics in the Department of Pediatrics. Her work focuses on the factors that contribute to adolescent morbidity and mortality associated with injury and violence. 